\title{
Barriers to Physical Activity: A Comparison of Afghans Living in the UK and Afghanistan
}

\author{
Ayazullah Safi ${ }^{1}$, Tony Myers ${ }^{2 *}$ \\ ${ }^{1}$ School of Life Sciences, University of Westminster, London, UK \\ ${ }^{2}$ Department of Social Science, Sport and Business, Newman University, Birmingham, UK \\ Email: *tony.myers@newman.ac.uk
}

How to cite this paper: Safi, A., \& Myers, T. (2021). Barriers to Physical Activity: A Comparison of Afghans Living in the UK and Afghanistan. Advances in Physical Education, $11,103-117$

https://doi.org/10.4236/ape.2021.111008

Received: January 21, 2021

Accepted: February 23, 2021

Published: February 26, 2021

Copyright (c) 2021 by author(s) and Scientific Research Publishing Inc. This work is licensed under the Creative Commons Attribution International License (CC BY 4.0).

http://creativecommons.org/licenses/by/4.0/

(c) (i) Open Access

\begin{abstract}
It is important to understand barriers to Physical Activity (PA), particularly for under researched populations. While a lack of PA has been acknowledged as an important issue for those living in Afghanistan, there have been no published studies exploring barriers to PA within this population. Therefore, the purpose of this study was to explore barriers to PA for Afghans and how these differ depending on where they reside: UK or Afghanistan. 930 participants, 578 (291 males; 287 females) were recruited from Afghanistan and 352 (267 males; 85 females) from the UK. A culturally nuanced questionnaire exploring barriers to PA was developed and used to collect data via an online survey software programme. Bayesian ordinal models explored differences between population groups, with results suggesting some barriers are shared across populations but others more pertinent for a particular group. Lack of time and being too tired were barriers for both populations, but were rated higher by those living in Afghanistan; as was a lack of confidence and being uncomfortable with exercise clothing. Afghan females perceived a lack of single-sex facilities, not being able to participate in PA with males, and having to be fully covered outside of the home as important barriers to their PA, but these were more of a barrier for those residing in the UK. The findings highlight important considerations for trying to engage these populations in PA.
\end{abstract}

\section{Keywords}

Physical Activity, Barriers, Afghans, Bayesian Modelling

\section{Introduction}

Despite the importance of physical activity (PA) for health and well-being being recognised for more than a century, $23 \%$ of adults remain insufficiently active 
across the globe (World Health Organization, 2018). To understand the nuances of this global issue, it is important to recognise that PA levels and importantly the barriers preventing people from engaging in PA are not homogeneous across countries, genders, education levels, socio-economic or cultural groups (Bauman et al., 2011; Guthold et al., 2018; Talaei et al., 2013).

Cultural expectations and acceptance of values of PA vary across countries and continents. Individuals from countries where PA is regarded as important for health are more likely to perceive fewer barriers to PA, and therefore, engage in more regular PA compared to countries where PA is not a social norm. For example, cultural attitudes towards PA and environmental differences were postulated as explanations for British participants being more active compared to counterparts in Saudi Arabia (Al-Nakeeb et al., 2012). Moreover, people from South Asian countries generally perceive more barriers to participating in regular PA and report lower levels of PA compared to European countries (Hallal et al., 2012).

Immigrant populations from countries with different cultural values and with a different socio-economic status to the host country, introduce an additional level of complexity. Migrants who are more acculturated are generally more physically active, faced with particular barriers, this positive effect is compromised (Hosper et al., 2007). This highlights the importance of understanding a particular group's barriers to PA when exploring positive acculturation in relation to PA.

Studies conducted in the UK, between migrants and the native population in terms of PA, have concluded that PA levels in the native population are higher than those of immigrant groups studied (Kruger \& Kohl III, 2008; Williams et al., 2011). One reason for this well may be that the barriers preventing people from participating in regular PA differ for particular ethnic and cultural groups. Identifying and understanding such barriers would be an important initial step in facilitating positive change. A number of studies have investigated different South Asian groups resident in the UK, including Bangladeshi, Indian and Pakistani communities (Dhawan \& Bray, 1997; Hayes et al., 2002; Lawton et al., 2006). Nonetheless, one growing migrant population that has not been investigated is the UK Afghan population. There were 63,000 Afghan-born residents in 2011 (Office for National Statistics, 2013), rising to an estimated 72,000 by 2019 (Office for National Statistics, 2019). While Afghans share similarities to some other British South Asian groups residing in the UK in terms of some cultural practices and religion, there are also likely to be differences and different levels of acculturation.

Afghanistan, the country of birth for this population, is very different to the UK on a number of levels, many of which impact on PA and the barriers to participation. It is a developing country recovering from over thirty years of war and still faces all the challenges this brings. At a national level, there is no national plan of action or strategy for PA, no national targets for PA in terms of noncommunicable disease prevention programmes integrated into primary health 
care services, and physical education is not mandatory to the school curriculum (World Health Organization \& Regional Office for the Eastern Mediterranean, 2015). In 2016, an estimated $88.1 \%$ of adolescents, failed to be physically active enough to meet the minimum widely accepted guidelines (Guthold et al., 2020). Given the important role PA has in the prevention of noncommunicable diseases (Lear et al., 2009; O'Donovan et al., 2013; Wang et al., 2005), these factors likely contribute to the high levels of noncommunicable diseases reported. The 2010 Afghanistan Mortality Survey (AMS) reported that over 33\% of all deaths were the result of noncommunicable diseases (Azimi et al., 2015) with cardiovascular diseases accounting for $16 \%$ of all mortality (Massahikhaleghi et al., 2018).

While this population has not previously been the subject of study into barriers to PA, a number of barriers have been identified in populations that share some cultural and religious values. For example, Muslim females end to limit their participation in $\mathrm{PA}$ or to confine it to their cultural and religious groups because of what are perceived to be negative associations with the Hijab (De Knop et al., 1996; Nakamura, 2002; Taylor \& Toohey, 2001; Zaman, 1997).

To address issues with low PA levels and implement successful PA interventions, it is important to understand barriers to PA for under researched populations such as Afghan people. To understand any barriers identified in this population, gaining an insight into how cultural norms impact upon PA is important, and one way to do this is to compare barriers experienced in different settings. Therefore, the aim of this study was to explore pertinent barriers to PA participation experienced by Afghan people. In particular, how these barriers to PA might differ depending on where individuals reside-UK or Afghanistan.

\section{Materials and Methods}

\subsection{Participants}

Following institutional ethical approval, an opportunity sample of 930 participants of Afghan origin were recruited and provided written informed consent for this study. 578 participants were recruited from Afghanistan, including 291 males (mean age $=29.88 \pm 6.43$ ), and 287 females (mean age $=30.08 \pm 6.48$ ), living either in Kabul or Jalalabad. 352 participants were recruited from the UK, 267 males (mean age $=30.46 \pm 9.54$ ), and 85 females (mean age $=29.36 \pm 8.62$, living either in Birmingham, London, or Manchester.

\subsection{Questionnaire Development}

The need for a culturally sensitive measure of barriers to PA for UK South Asians was identified. The initial phase of development of this measure involved recruiting 20 participants (11 male and 9 female) from different South Asian cultural groups from the UK. Semi-structured interviews were then conducted to explore what participants felt were barriers to participating in PA for members

of their cultural group. The themes generated from these interviews were used to 
produce a series of 20 questions. These questions were used in the initial pilot study and given to 50 (29 males, 21 females) from the South Asian background. Following the exploratory factor analysis, the questions reduced to 11 which participants rated 1-10. Rating-1 if participants strongly disagreed with the statement, 5 if neither agreed nor disagree, and 10 if they strongly agreed (see Table 1).

\subsection{Procedure}

Following institutional ethical approval, an online version of the ABPA questionnaire along with additional demographic information was collected using Qualtrics (http://www.qualtrics.com/) an online survey software programme. Links to questionnaires were shared with participants either by email, smartphone or more directly using a laptop computer provided by the researchers. The majority of the participants, particularly those residing in Afghanistan, chose to complete the online survey on a laptop provided.

\subsection{Data Analysis}

Descriptive statistics were calculated and are presented as mean \pm standard deviation along with median \pm median absolute deviation (MAD) given some data were skewed.

While the ABPA questionnaire demonstrated acceptable factor validity using common measures of fit for some underlying latent factors, it was decided that it would be more informative to make comparisons of individual questions rather than consider composite scores. Individual Likert-style questions, such as the one used in the ABPA questionnaire, produce ratings that cannot be assumed equidistant and so it is inappropriate to fit metric models to this type of data (Liddell \& Kruschke, 2018). Likert-style responses are more appropriately modelled using ordinal regression where the models assume observed ratings originate

Table 1. Adults Barriers to Physical Activity (ABPA) Questions.

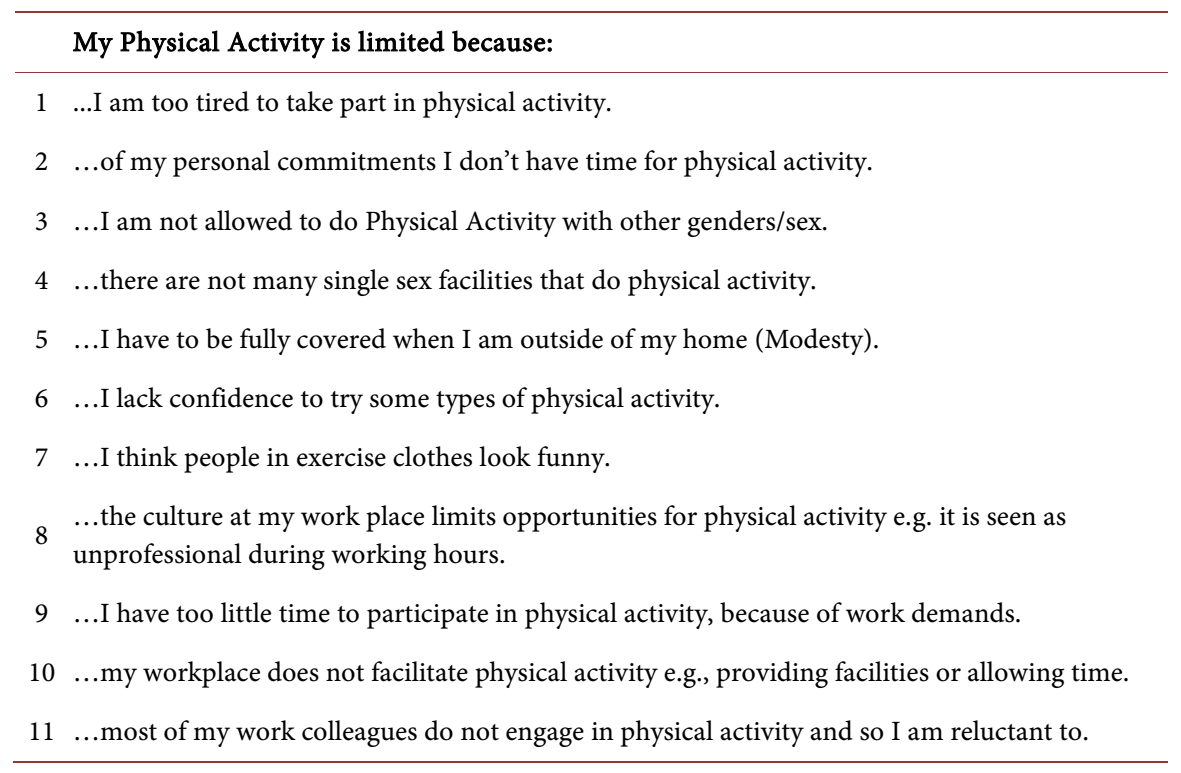


from categorising a latent continuous variable (Bürkner \& Vuorre, 2019). Therefore, responses to each question in the ABPA questionnaire were modelled using two types of Bayesian cumulative ordinal models, the first assuming equal variances across responses by those Afghans resident in the UK and those living in Afghanistan and the second allowing variances in these populations to differ by explicitly modelling sigma as group level standard deviation.

To determine which of the two types of models fitted best explained the data, a model comparison approach was taken. The models produced were compared using Leave-One-Out cross-validation (LOO), a method of estimating pointwise out-of-sample prediction accuracy from fitted Bayesian models using log-likelihoods from posterior simulations of the parameter values (Vehtari et al., 2017). The best models, in terms of out-of-sample prediction accuracy, are those with the lowest LOO Information Criterion (LOOIC). A LOOIC difference greater than twice its corresponding standard error considered to suggest that the model with a lower LOOIC value fitted the data substantially better (Bürkner \& Vuorre, 2019). To look for systematic discrepancies between real and simulated data for each model, the predictive distribution yrep compared to the observed data y (Gabry et al., 2019).

In addition, two additional metrics were calculated: a Bayesian version of R2 and the Probability of Direction (pd). While Bayesian R2 can be considered analogous to a traditional Coefficient of Determination, it is defined more accurately as an estimate of the proportion of variance explained for new data (Gelman et al., 2019). Probability of Direction is defined as the proportion of the posterior distribution that has the same sign as the median of the distribution and interpreted as the probability of a difference (between $50 \%$ and $100 \%$ ) in a particular direction.

\section{Results}

There were a number of differences between the Afghan nationals residing in the UK compared to those living in Afghanistan in terms of barriers to PA.

\subsection{Too Tired}

The best fitting ordinal model exploring differences in the ratings for feeling too tired as a barrier to PA (Q1) predicts that $70 \%$ of all Afghans, irrespective of where they reside, identify this as a barrier. Nonetheless, Afghans living in Afghanistan perceive this more of a barrier than those residing in the UK. Participants living in Afghanistan rate being too tried as barrier to their PA 0.72 (95\% CI 0.49:0.95) of a standard deviation higher than UK based Afghans. Translated into a common language effect, this means that there is a $69.5 \%$ chance that a person picked at random from the those residing in Afghanistan rate this higher than a person picked at random from Afghans living in the UK. The probability that these groups differ is very high ( $\mathrm{pd}=100 \%)$. The model predicts a $60.6 \%$ chance that Afghans living in Afghanistan consider feeling too tired as a barrier 
to their PA, although only $1.72 \%$ chance they rate this barrier a ten (strongly agree), but with a $39.82 \%$ chance of giving a rating of seven (see Figure 1 (A)).

\subsection{Lack of Time}

The model suggests that a lack of time for PA (Q2) was perceived as a barrier by all Afghans with a $75.93 \%$ chance they would rate this as a barrier. However, this was perceived to be more of a barrier for Afghans living in Afghanistan than those living in the UK (0.84 SD higher, 95\% CI =0.63:1.06). Seen difference
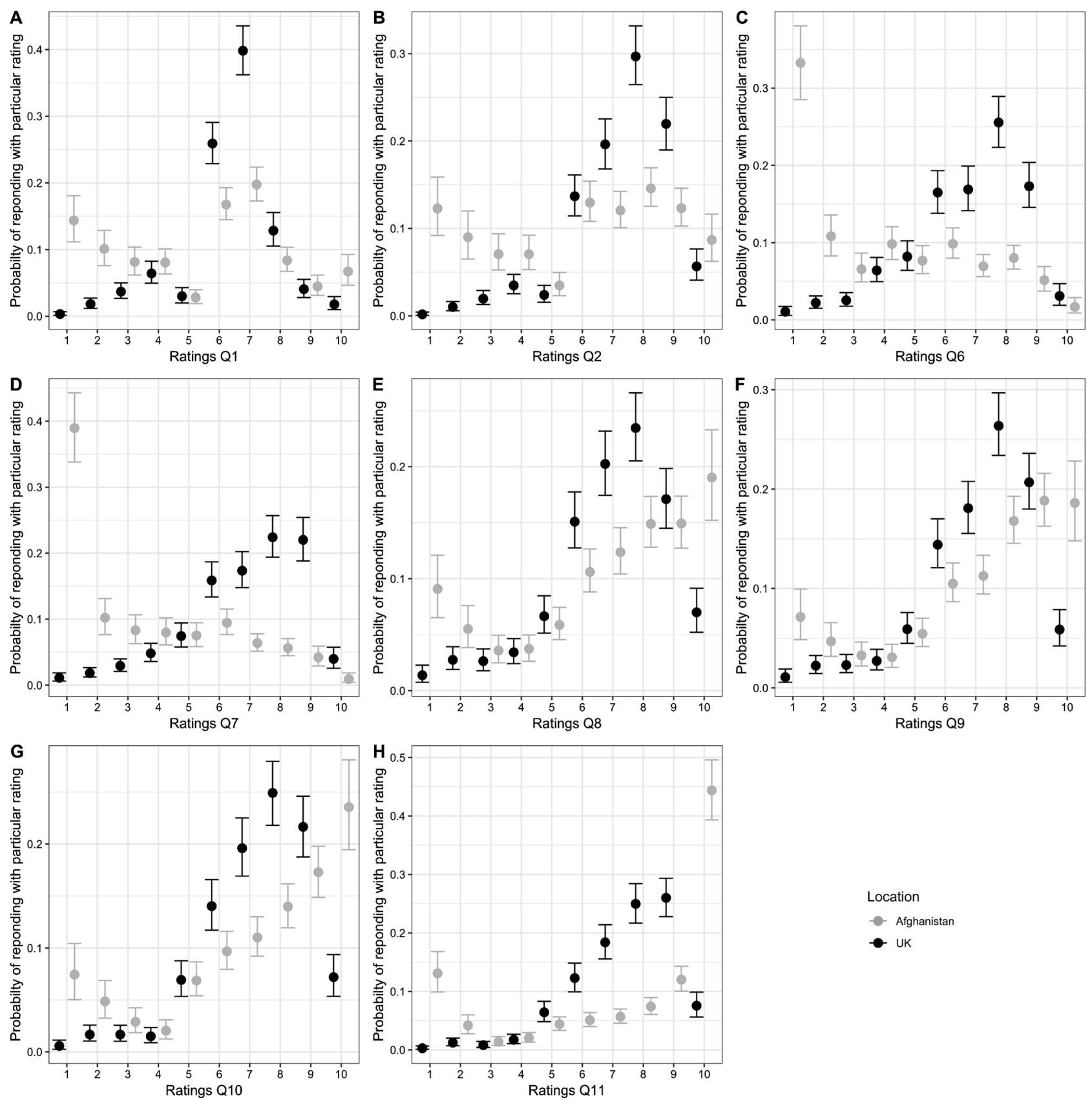

Figure 1. The probabilities and 95\% credible intervals of responses by Afghans living in the UK and Afghanistan to questions (A) Q1; (B) Q2; (D) Q7; (E) Q8; (F) Q9; (G) Q10; (H) Q11. 
considered in terms of a common language effect, this difference represents $72.4 \%$ chance that person picked at random from Afghans living in Afghanistan would rate this barrier higher than an Afghan living in the UK picked at random. Overall, there is a high probability of a difference between groups ( $\mathrm{pd}=$ $100 \%)$. Afghan nationals residing in the UK have a higher probability of strongly agreeing that this barrier is problematic for their PA $(8.70 \%$ compared to $5.67 \%)$, but this estimate has a high level of uncertainty. Afghans living in Afghanistan are far more likely to rate lack of time as impacting on their PA compared to their UK based compatriots, with a $19.62 \%$ compared to a $12.06 \%$ chance of giving a rating of seven, a $29.68 \%$ compared to $14.58 \%$ chance of giving a rating of eight, and a or $21.97 \%$ compared to a $12.33 \%$ chance or giving a rating of nine (see Figure 1(B)).

\subsection{A lack of Confidence to Try Some Types of Physical Activity}

Confidence to try different types of PA was higher in the UK, a lack of confidence proving a bigger barrier for Afghan nationals residing in Afghanistan with 1.60 (95\% CI $=1.37: 1.84)$ standard deviations higher than those Afghan nationals residing in the UK. The probability of this difference is very high ( $\mathrm{pd}=$ $100 \%)$. The size of difference expressed in terms of a common language effect, suggests that here is an $87.4 \%$ chance that a person picked at random from Afghan nationals residing in Afghanistan would rate lack of confidence to try some types of PA as a barrier (see Figure $1(\mathrm{C})$ ).

\subsection{Exercise Clothes Look Funny}

A similar trend was found in perceptions of the way individuals look in exercise clothes, for those residing in Afghanistan this barrier was 1.86 (95\% CI = 1.62:2.12) standard deviations higher than for those residing in the UK. Overall, this represents a very high probability of a difference $(\mathrm{pd}=100 \%)$ and the size of difference suggesting a $90.6 \%$ chance that a person picked at random from Afghan nationals will award a higher rating to this barrier than a person picked at random from UK based Afghans. The model predicts that Afghans residing in Afghanistan have an $81.58 \%$ chance of considering exercise clothing a barrier, compared to $26.59 \%$ for those residing in the UK. Not only is there $72.96 \%$ chance of those residing in the UK not considering exercise clothes a barrier, but $38.94 \%$ of Afghans resident in UK are predicted to 'strongly disagree' that exercise this will impact on their participation in PA rating this a one (see Figure 1(D)).

\subsection{The Culture the Workplace Limits Opportunities for PA; Workplace Not Facilitating PA; and Work Demands}

There are some barriers that impact both groups equally. Workplace culture, work demands and their workplace not facilitating PA were equally limiting to PA for individuals in both locations. All differences in these barriers were very 
small and some highly uncertain (workplace culture [pd $=57.23 \%$ ], work demands [pd $=84.25 \%]$, not facilitating PA [pd $=84.25 \%]$ ), but had an important impact on both groups. The model predicts that Afghans living in Afghanistan have an $82.29 \%$ chance of considering the culture their workplace limiting opportunities for PA as a barrier, compared to $71.82 \%$ chance for UK based Afghans. While the differences between groups were again minimal and uncertain, both groups also perceived work demands to impact on their PA, the model estimates an $85.39 \%$ chance Afghans living in Afghanistan and 75.97\% of Afghans living in the UK rate this as a barrier to their PA engagement (see Figure 1(F)). Similar ratings were given for their workplace not facilitating PA. There is an $87.41 \%$ chance that Afghans living in Afghanistan rate this a barrier, compared to a $75.52 \%$ chance UK based Afghans (see Figures 1(E)-(G)).

\subsection{Work Colleagues Do Not Engage in Physical Activity}

UK based Afghans saw work colleagues not engaging in PA as more of a barrier than those living in Afghanistan. The model suggests this barrier was 0.97 of a standard deviation higher $(95 \% \mathrm{CI}=0.56: 1.41)$ for UK residents which represents a high probability of a difference $(\mathrm{pd}=100 \%)$. In terms of a common language effect, this degree of difference suggests there is a $75.4 \%$ chance that a person picked at random from UK based Afghans would rate this barrier higher than someone living in Afghanistan. The model predicts there is a $19.03 \%$ chance that UK resident Afghans "strongly agree" this is barrier, compared with 7.00\% chance for those residing in Afghanistan (see Figure 1(H)).

\subsection{Females: Not Able to Participate in PA with Males}

UK resident Afghan females tended to perceive particular barriers having a bigger impact on their lack of PA than their counterparts living in Afghanistan. The model predicts that wherever they reside, $91.5 \%$ of Afghan females rate not being able to participate in PA with males a barrier to their PA. However, this was higher for Afghan females living in the UK compared to those living in Afghanistan by a magnitude of 0.98 ( $95 \% \mathrm{CI}=0.41: 1.61)$ of a standard deviation different. This represents a very high probability of a difference $(\mathrm{pd}=100 \%)$. Translated into a common language effect, this size of difference means that there is a 75.6\% chance that an Afghan female picked at random from those residing in the UK would rate this barrier higher than a female picked at random from those living in Afghanistan. Considering the actual ratings, there is 33\% chance UK based Afghan females "strongly agree" that this was a barrier to their PA rating this a ten. In contrast, only $2 \%$ of Afghan based females felt this strongly (see Figure 2(A)).

\subsection{Females: Lack of Single-Sex Facilities}

91.94\% of Afghan females, irrespective of country of residence, rate the lack of single-sex facilities as a barrier to their PA. Nevertheless, this was seen as more 

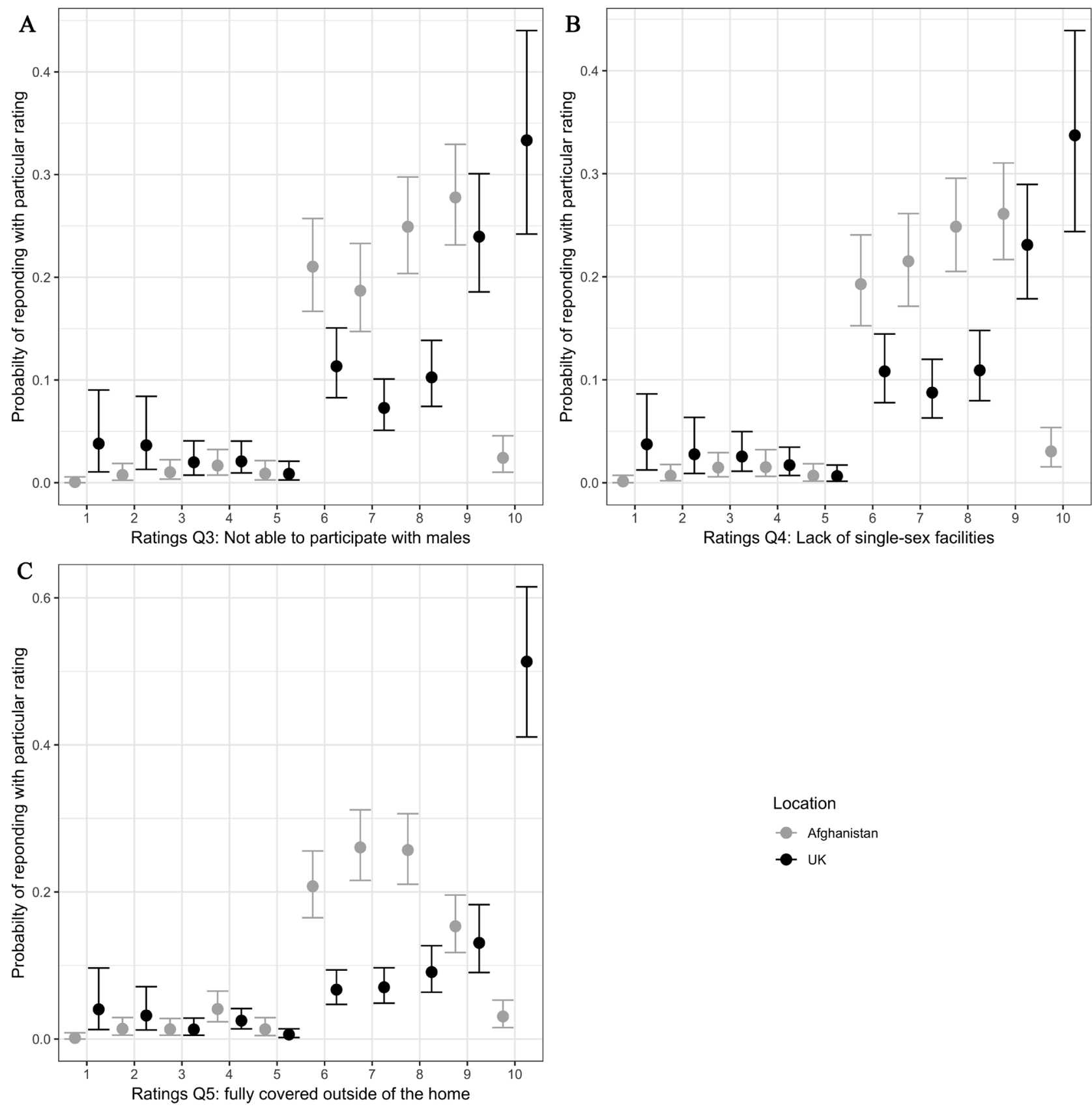

Figure 2. The probabilities and 95\% credible intervals of responses by Female Afghans living in the UK and Afghanistan to question my physical activity is limited because (I) Q3; (J) Q4; K) Q5.

of a barrier to female Afghans resident in the UK compared to those who reside in Afghanistan by 0.95 (95\% CI $=0.41: 1.54)$ of a standard deviation, again this represents a very high probability of a difference $(\mathrm{pd}=100 \%)$. This magnitude of difference expressed in terms of a common language effect, suggests a $74.9 \%$ chance that a person picked at random from UK Afghan females would rate this barrier higher than those resident in Afghanistan. The model predicts UK Afghan females have a $34 \%$ chance of strongly agreeing this is a barrier for them, with only $3 \%$ of Afghan based females feeling as strongly (see Figure 2(B)). 


\subsection{Females: Having to Be Fully Covered Outside of the Home}

The model estimates that $89.89 \%$ of all females, irrespective of where they live, would agree that having to be fully covered outside of the home is a barrier to their PA. However, this barrier is still the largest difference between UK and Afghan based females of all the barriers they rated, with 1.99 (95\% CI = 1.26:2.85) standard deviations higher for UK residents compared to females that residing in Afghanistan. This suggests a very high probability of a difference (pd-100\%). with the magnitude of difference representing a $92 \%$ chance that an Afghan female picked at random from the UK will rate this barrier higher than a female picked at random from Afghanistan. The model predicts a $51.23 \%$ chance that UK based Afghan females "strongly agree" that this is a barrier to their PA, compared to 3.06\% of females living in Afghanistan (see Figure 2(C)).

\section{Discussion}

This is the first study to explore barriers to PA participation experienced by Afghan people, and, in particular, how these barriers might PA differ depending where individuals reside. The findings provide some novel insights into perceived barriers to PA in Afghan people, as well as confirming some cross-cultural trends-particularly those shared with others that have similar religious beliefs and cultural practices.

Consistent with the findings of a number of studies across cultural groups (e.g. Blake et al., 2017; Cerin et al., 2010; Conway et al., 2017; Edmunds et al., 2013; Santos et al., 2016), a perceived lack of time is a barrier for Afghan people in general. Being too tired to participate in PA was similarly seen as is an important barrier regardless of their country of residence. Nonetheless, there is a very high probability that both of these barriers are seen as more of a barrier for those living in Afghanistan. The longer working week in Afghanistan may explain this. Conversely, UK based Afghans see work colleagues not engaging in PA as more of a barrier than those living in Afghanistan. This sensitivity to the behavior of work colleagues may well be a reflection of a wider need to be perceived as similar to the UK population more generally. Equally, this could just be the result of the fact that engaging in PA is considered unusual behavior for those living in Afghanistan, and engaging in PA with work colleagues even more unusual.

Some of the differences in barriers to PA between Afghans living in the UK and those living in Afghanistan do provide support for a positive acculturation hypothesis. This was particularly the case as UK based Afghans do not seem lack confidence to engage in different types of PA activity and also seem more comfortable with the attire associated with particular types of formalized PA. There is a very high probability that those living in Afghanistan lack the confidence to engage in some types of physical activity to a far greater degree than their UK based compatriots and also perceive exercise clothes as funny. Previous research has identified confidence a key factor to engaging in PA (Trost et al., 2002; Withall et al., 2011) and clothing has previously been identified as a barrier to 
PA for people from South Asian communities (Rathanaswami et al., 2016). A reason for the differences found in the present study may well be due to a lack of familiarity with, or distrust of, commercial PA practices that are seen as imbued with western cultural values for those residing in Afghanistan. Anecdotal support for this finding comes from observations of Afghan males engaging in formal gym training wearing the traditional Afghan clothing.

Despite the UK having a more far more PA supportive infrastructure and resources dedicated to increasing PA levels than Afghanistan, Afghan females living in the UK feel some aspects of their daily life are more of a barrier to PA than Afghan females living in Afghanistan do. Barriers such as a lack of single-sex facilities, not being able to participate in PA with males, and having to be fully covered outside of the home, are identified as important by all Afghan females irrespective of where they reside, nonetheless, these are perceived to be more of a barrier for UK based females. This is something that is supported by previous research that investigated barriers to PA in South Asian groups in general and veiled Muslim females in particular (Babakus \& Thompson, 2012; Darr et al., 2008; Farooqi et al., 2000; Kelly et al., 2016; McGuire, 2015; Siddiqui et al., 2008; Sriskantharajah \& Kai, 2007; Tinker et al., 2017; Walseth \& Fasting, 2003). Nonetheless, it is interesting that there is a very high probability that Afghan females residing in the UK see all of these as more of as barrier than those living in Afghanistan. While this could just represent a disconnect in the opportunities and an awareness of the need for PA in terms of health benefits, equally it could reflect the lack of an appropriate PA infrastructure to support for Muslim females PA in the UK. In Afghanistan, male and females are always segregated in facilities such as gyms, exercise classes as well as sports facilities, which is not the case in the UK.

\section{Practical Implications}

This research will open doors for other researchers to focus on Afghan population in other western countries, as well allowing comparisons with ethnic minority groups in terms of barriers to PA. For Afghanistan, the research has highlighted a need for public health policies in Afghanistan to aim to normalize PA in general and to support work-based initiatives and interventions where possible. While not explicitly mentioned, a greater emphasis on the benefits of PA would be useful alongside much needed investment. There is also clearly a need for single-sex facilities, or at least more dedicated single-sex PA related sessions made available in the UK and Afghanistan.

\section{Conclusion}

The study provides some unique insights into barriers to PA between genders, country of residence. The research reported here is novel in several ways: it is the first study to explore barriers to PA in UK based Afghan migrants and make comparisons with their compatriots in Afghanistan; it introduces a new measure 
for exploring barriers to PA that is relevant to many South Asian communities; and finally, it is the first study to analyze barriers to PA using Bayesian ordinal regression models - a type of analysis that has a number of advantages over the traditional analysis methods employed in this area.

To summarize, a lack of time and being too tired to participate in PA are seen as barriers for all Afghans-regardless of where they live. Nonetheless, those living in Afghanistan rate these barriers higher than those residing in the UK. A lack of confidence to engage in some types of PA is a barrier for those living in Afghanistan, as is the type of clothing often worn when engaging in exercise. While in general, Afghan females see a lack of single-sex facilities, not being able to participate in PA with males, and having to be fully covered outside of the home as important barriers to their PA. Nonetheless, these were seen as more of a barrier for those residing in the UK. Some of the issues highlighted are important considerations for those trying to engage these populations in PA.

\section{Conflicts of Interest}

The authors declare no conflicts of interest regarding the publication of this paper.

\section{References}

Al-Nakeeb, Y., Lyons, M., Collins, P., Al-Nuaim, A., Al-Hazzaa, H., Duncan, M. J., \& Nevill, A. (2012). Obesity, Physical Activity and Sedentary Behavior amongst British and Saudi Youth: A Cross-Cultural Study. International Journal of Environmental Research and Public Health, 9, 1490-1506. https://doi.org/10.3390/ijerph9041490

Azimi, M. D., Najafizada, S. A. M., Khaing, I. K., \& Hamajima, N. (2015). Factors Influencing Non-Institutional Deliveries in Afghanistan: Secondary Analysis of the Afghanistan Mortality Survey 2010. Nagoya Journal of Medical Science, 77, 133-143.

Babakus, W. S., \& Thompson, J. L. (2012). Physical Activity among South Asian Women: A Systematic, Mixed-Methods Review. International Journal of Behavioral Nutrition and Physical Activity, 9, Article No. 150. https://doi.org/10.1186/1479-5868-9-150

Bauman, A., Ma, G., Cuevas, F., Omar, Z., Waqanivalu, T., Phongsavan, P., Keke, K., Bhushan, A., \& Equity and Non-Communicable Disease Risk Factors Project Collaborative Group (2011). Cross-National Comparisons of Socioeconomic Differences in the Prevalence of Leisure-Time and Occupational Physical Activity, and Active Commuting in Six Asia-Pacific Countries. Journal of Epidemiology \& Community Health, 65, $35-43$.

Blake, H., Stanulewicz, N., \& Mcgill, F. (2017). Predictors of Physical Activity and Barriers to Exercise in Nursing and Medical Students. Journal of Advanced Nursing, 73, 917-929. https://doi.org/10.1111/jan.13181

Bürkner, P.-C., \& Vuorre, M. (2019). Ordinal Regression Models in Psychology: A Tutorial. Advances in Methods and Practices in Psychological Science, 2, 77-101.

https://doi.org/10.1177/2515245918823199

Cerin, E., Leslie, E., Sugiyama, T., \& Owen, N. (2010). Perceived Barriers to Leisure-Time Physical Activity in Adults: An Ecological Perspective. Journal of Physical Activity and Health, 7, 451-459. https://doi.org/10.1123/jpah.7.4.451

Conway, J., Tsourtos, G., \& Lawn, S. (2017). The Barriers and Facilitators That Indige- 
nous Health Workers Experience in Their Workplace and Communities in Providing Self-Management Support: A Multiple Case Study. BMC Health Services Research, 17, Article No. 319. https://doi.org/10.1186/s12913-017-2265-5

Darr, A., Astin, F., \& Atkin, K. (2008). Causal Attributions, Lifestyle Change, and Coronary Heart Disease: Illness Beliefs of Patients of South Asian and European Origin Living in the United Kingdom. Heart \& Lung, 37, 91-104.

https://doi.org/10.1016/j.hrtlng.2007.03.004

De Knop, P., Theeboom, M., Wittock, H., \& De Martelaer, K. (1996). Implications of Islam on Muslim Girls' Sport Participation in Western Europe. Literature Review and Policy Recommendations for Sport Promotion. Sport, Education and Society, 1, 147-164. https://doi.org/10.1080/1357332960010202

Dhawan, J., \& Bray, C. L. (1997). Asian Indians, Coronary Artery Disease, and Physical Exercise. Heart, 78, 550-554.

Edmunds, S., Hurst, L., \& Harvey, K. (2013). Physical Activity Barriers in the Workplace: An Exploration of Factors Contributing to Non-Participation in a UK Workplace Physical Activity Intervention. International Journal of Workplace Health Management, 6, 227-240. https://doi.org/10.1108/IJWHM-11-2010-0040

Farooqi, A., Nagra, D., Edgar, T., \& Khunti, K. (2000). Attitudes to Lifestyle Risk Factors for Coronary Heart Disease amongst South Asians in Leicester: A Focus Group Study. Family Practice, 17, 293-297. https://doi.org/10.1093/fampra/17.4.293

Gabry, J., Simpson, D., Vehtari, A., Betancourt, M., \& Gelman, A. (2019). Visualization in Bayesian Workflow. Journal of the Royal Statistical Society: Series A (Statistics in Society), 182, 389-402. https://doi.org/10.1111/rssa.12378

Gelman, A., Goodrich, B., Gabry, J., \& Vehtari, A. (2019). R-Squared for Bayesian Regression Models. The American Statistician, 73, 307-309. https://doi.org/10.1080/00031305.2018.1549100

Guthold, R., Stevens, G. A., Riley, L. M., \& Bull, F. C. (2018). Worldwide Trends in Insufficient Physical Activity from 2001 to 2016: A Pooled Analysis of 358 Population-Based Surveys with 1.9 Million Participants. The Lancet Global Health, 6, e1077-e1086. https://doi.org/10.1016/S2214-109X(18)30357-7

Guthold, R., Stevens, G. A., Riley, L. M., \& Bull, F. C. (2020). Global Trends in Insufficient Physical Activity among Adolescents: A Pooled Analysis of 298 Population-Based Surveys with 1.6 Million Participants. The Lancet Child \& Adolescent Health, 4, 23-35. https://doi.org/10.1016/S2352-4642(19)30323-2

Hallal, P. C., Andersen, L. B., Bull, F. C., Guthold, R., Haskell, W., Ekelund, U., \& Group, L. P. A. S. W. (2012). Global Physical Activity Levels: Surveillance Progress, Pitfalls, and Prospects. The Lancet, 380, 247-257. https://doi.org/10.1016/S0140-6736(12)60646-1

Hayes, L., White, M., Unwin, N., Bhopal, R., Fischbacher, C., Harland, J., \& Alberti, K. (2002). Patterns of Physical Activity and Relationship with Risk Markers for Cardiovascular Disease and Diabetes in Indian, Pakistani, Bangladeshi and European Adults in a UK Population. Journal of Public Health, 24, 170-178.

https://doi.org/10.1093/pubmed/24.3.170

Hosper, K., Klazinga, N. S., \& Stronks, K. (2007). Acculturation Does Not Necessarily Lead to Increased Physical Activity during Leisure Time: A Cross-Sectional Study among Turkish Young People in the Netherlands. BMC Public Health, 7, Article No. 230. https://doi.org/10.1186/1471-2458-7-230

Kelly, S., Martin, S., Kuhn, I., Cowan, A., Brayne, C., \& Lafortune, L. (2016). Barriers and Facilitators to the Uptake and Maintenance of Healthy Behaviours by People at 
Mid-Life: A Rapid Systematic Review. PLoS ONE, 11, e0145074.

https://doi.org/10.1371/journal.pone.0145074

Kruger, J., \& Kohl III, H. W. (2008). Prevalence of Regular Physical Activity among Adults-United States, 2001 and 2005. JAMA, 299, 30-32.

https://doi.org/10.1001/jama.299.1.30

Lawton, J., Ahmad, N., Hanna, L., Douglas, M., \& Hallowell, N. (2006). “I Can’t Do Any Serious Exercise": Barriers to Physical Activity amongst People of Pakistani and Indian Origin with Type 2 Diabetes. Health Education Research, 21, 43-54. https://doi.org/10.1093/her/cyh042

Lear, S. A., Humphries, K. H., Hage-Moussa, S., Chockalingam, A., \& Mancini, G. J. (2009). Immigration Presents a Potential Increased Risk for Atherosclerosis. Atherosclerosis, 205, 584-589. https://doi.org/10.1016/j.atherosclerosis.2008.12.037

Liddell, T. M., \& Kruschke, J. K. (2018). Analyzing Ordinal Data with Metric Models: What Could Possibly Go Wrong? Journal of Experimental Social Psychology, 79, 328-348. https://doi.org/10.1016/j.jesp.2018.08.009

Massahikhaleghi, P., Tehrani-Banihashemi, A., Saeedzai, S. A., Hossaini, S. M., Hamedi, S. A., Moradi-Lakeh, M., Naghavi, M., Murray, C. J., \& Mokdad, A. H. (2018). Burden of Diseases and Injuries in Afghanistan, 1990-2016: Findings from the Global Burden of Disease 2016 Study. Archives of Iranian Medicine (AIM), 21, 324-334.

McGuire, A. M. (2015). Benefits and Barriers to Exercise in Midlife Women Undertaking a Web-Based Multi-Modal Lifestyle Intervention for the Primary Prevention of Chronic Disease. Brisbane: Queensland University of Technology.

Nakamura, Y. (2002). Beyond the Hijab: Female Muslims and Physical Activity. Women in Sport and Physical Activity Journal, 11, 21-48. https://doi.org/10.1123/wspaj.11.2.21

O’Donovan, G., Hillsdon, M., Ukoumunne, O. C., Stamatakis, E., \& Hamer, M. (2013). Objectively Measured Physical Activity, Cardiorespiratory Fitness and Cardiometabolic Risk Factors in the Health Survey for England. Preventive Medicine, 57, 201-205. https://doi.org/10.1016/j.ypmed.2013.05.022

Office for National Statistics (2013). Immigration Patterns of Non-UK Born Populations in England and Wales in 2011.

Office for National Statistics (2019). Population of the UK by Country of Birth and Nationality. London: Office for National Statistics.

https://www.ons.gov.uk/peoplepopulationandcommunity/populationandmigration/int ernationalmigration/datasets/populationoftheunitedkingdombycountryofbirthandnatio nality

Rathanaswami, K., Bengoechea, E. G., \& Bush, P. L. (2016). Physical Activity in First Generation South Asian Women Living in Canada: Barriers and Facilitators to Participation. Women in Sport and Physical Activity Journal, 24, 110-119. https://doi.org/10.1123/wspaj.2015-0019

Santos, I., Ball, K., Crawford, D., \& Teixeira, P. J. (2016). Motivation and Barriers for Leisure-Time Physical Activity in Socioeconomically Disadvantaged Women. PLoS ONE, 11, e0147735. https://doi.org/10.1371/journal.pone.0147735

Siddiqui, F. R., Bhatti, M. A., \& Shahid, A. (2008). Knowledge, Attitudes and Practices to Lifestyle Risk Factors for Coronary Heart Disease (CHD) and Diabetes amongst South Asians in North Kirklees, England-A Focus Group Study. Pakistan Armed Forces Medical Journal, 58, 304-311.

Sriskantharajah, J., \& Kai, J. (2007). Promoting Physical Activity among South Asian Women with Coronary Heart Disease and Diabetes: What Might Help? Family Practice, 24, 71-76. https://doi.org/10.1093/fampra/cml066 
Talaei, M., Rabiei, K., Talaei, Z., Amiri, N., Zolfaghari, B., Kabiri, P., \& Sarrafzadegan, N. (2013). Physical Activity, Sex, and Socioeconomic Status: A Population-Based Study. ARYA Atherosclerosis, 9, 51-60.

Taylor, T., \& Toohey, K. (2001). Behind the Veil: Exploring the Recreation Needs of Muslim Women. Leisure/Loisir, 26, 85-105. https://doi.org/10.1080/14927713.2001.9649930

Tinker, A., Molloy, L., Monks, I., Pennells, L., Russell, E., \& Haines, E. (2017). The Benefits and Barriers of Exercise for the Physical Health of Older Women. Journal of Aging, Research and Clinical Practice, 6, 73-79.

Trost, S. G., Owen, N., Bauman, A. E., Sallis, J. F., \& Brown, W. (2002). Correlates of Adults' Participation in Physical Activity: Review and Update. Medicine \& Science in Sports \& Exercise, 34, 1996-2001. https://doi.org/10.1097/00005768-200212000-00020

Vehtari, A., Gelman, A., \& Gabry, J. (2017). Practical Bayesian Model Evaluation Using Leave-One-Out Cross-Validation and WAIC. Statistics and Computing, 27, 1413-1432. https://doi.org/10.1007/s11222-016-9696-4

Walseth, K., \& Fasting, K. (2003). Islam's View on Physical Activity and Sport: Egyptian Women Interpreting Islam. International Review for the Sociology of Sport, 38, 45-60. https://doi.org/10.1177/10126902030381003

Wang, L., Kong, L., Wu, F., Bai, Y., \& Burton, R. (2005). Preventing Chronic Diseases in China. The Lancet, 366, 1821-1824. https://doi.org/10.1016/S0140-6736(05)67344-8

Williams, E. D., Stamatakis, E., Chandola, T., \& Hamer, M. (2011). Physical Activity Behaviour and Coronary Heart Disease Mortality among South Asian People in the UK: An Observational Longitudinal Study. Heart, 97, 655-659. https://doi.org/10.1136/hrt.2010.201012

Withall, J., Jago, R., \& Fox, K. R. (2011). Why Some Do but Most Don't. Barriers and Enablers to Engaging Low-Income Groups in Physical Activity Programmes: A Mixed Methods Study. BMC Public Health, 11, Article No. 507.

https://doi.org/10.1186/1471-2458-11-507

World Health Organization (2018). Physical Activity, Key Facts. Http://www.who.int/News-Room/Fact-Sheets/Detail/Physical-Activity

World Health Organization, Regional Office for the Eastern Mediterranean (2015). Country Factsheet Insufficient Physical Activity: Afghanistan. WHO-EM/HED/126/E. WHO IRIS. https://apps.who.int/iris/handle/10665/204240

Zaman, H. (1997). Islam, Well-Being and Physical Activity: Perceptions of Muslim Young Women. In G. Clarke, \& B. Humberstone (Eds.), Researching Women and Sport (pp. 50-67). London: Palgrave Macmillan. https://doi.org/10.1007/978-1-349-25317-3_4 